\title{
Laser Science and Technology Program Update 2001
}

\author{
L.A. Hackel, H.L. Chen
}

January 1, 2002

U.S. Department of Energy

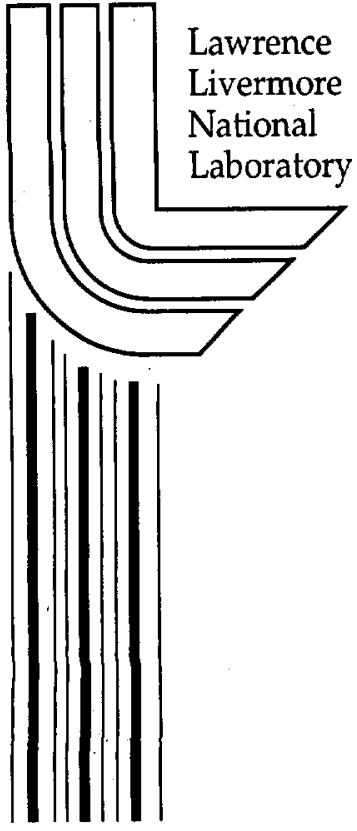

Approved for public release; further dissemination unlimited 


\section{DISCLAIMER}

This document was prepared as an account of work sponsored by an agency of the United'States Government. Neither the United States Government nor the University of California nor any of their employees, makes any warranty, express or implied, or assumes any legal liability or responsibility for the accuracy, completeness, or usefulness of any information, apparatus, product, or process disclosed, or represents that its use would not infringe privately owned rights. Reference herein to any specific commercial product, process, or service by trade name, trademark, manufacturer, or otherwise, does not necessarily constitute or imply its endorsement, recommendation, or favoring by the United States Government or the University of California. The views and opinions of authors expressed herein do not necessarily state or reflect those of the United States Government or the University of California, and shall not be used for advertising or product endorsement purposes.

This work was performed under the auspices of the U.S. Department of Energy by the University of California, Lawrence Livermore National Laboratory under Contract No. W-7405-Eng-48.

This report has been reproduced directly from the best available copy.

Available electronically at http://www.doe.gov/bridge

Available for a processing fee to U.S. Department of Energy

and its contractors in paper from

U.S. Department of Energy

Office of Scientific and Technical Information

P.O. Box 62

Oak Ridge, TN 37831-0062

Telephone: (865) 576-8401

Facsimile: (865) 576-5728

E-mail: reports@adonis.osti.gov

Available for the sale to the public from

U.S. Department of Commerce

National Technical Information Service

5285 Port Royal Road

Springfield, VA 22161

Telephone: (800) 553-6847

Facsimile: (703) 605-6900

E-mail: orders@ntis.fedworld.gov

Online ordering: http://www.ntis.gov/ordering.htm

OR

Lawrence Livermore National Laboratory

Technical Information Department's Digital Library

http://www.llnl.gov/tid/Library.html 


\title{
LaSER SCIENCE AND TeChNOLOGY Program Update 2001
}

\author{
L. A. Hackel and H. L. Chen
}

\section{January 2002}

LAWRENCE LIVERMORE NATIONAL LABORATORY

University of California $\bullet$ Livermore, California $\bullet 94550$ 


\section{TABle Of Contents}

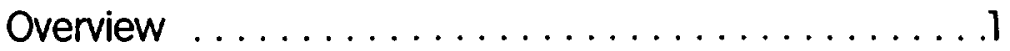

Deploying NIF Hardware and Improving NIF Laser Optics and Materials Performance .......... .

Construction and Testing of Z-Beamlet Completed; Laser Trigger System Delivered .................3

kW- to MW-Class Solid-State Laser Technology for Inertial Fusion Energy . . . . . . . . . . . . . . . . .4

Solid-State Heat Capacity Laser for the Department of Defense ....................6

Advance Solid-State Lasers for Government and Industry .........................

High-Energy Ultrashort-Pulse Laser Technology . . . . . .99

Large-Scale Diffractive Optics and Adaptive Optics for Space, NIF, and Petawatt Applications ..........................10

Laser Guide Star Systems for Ground-Based Observatories 


\section{Laser Science and Technology Program}

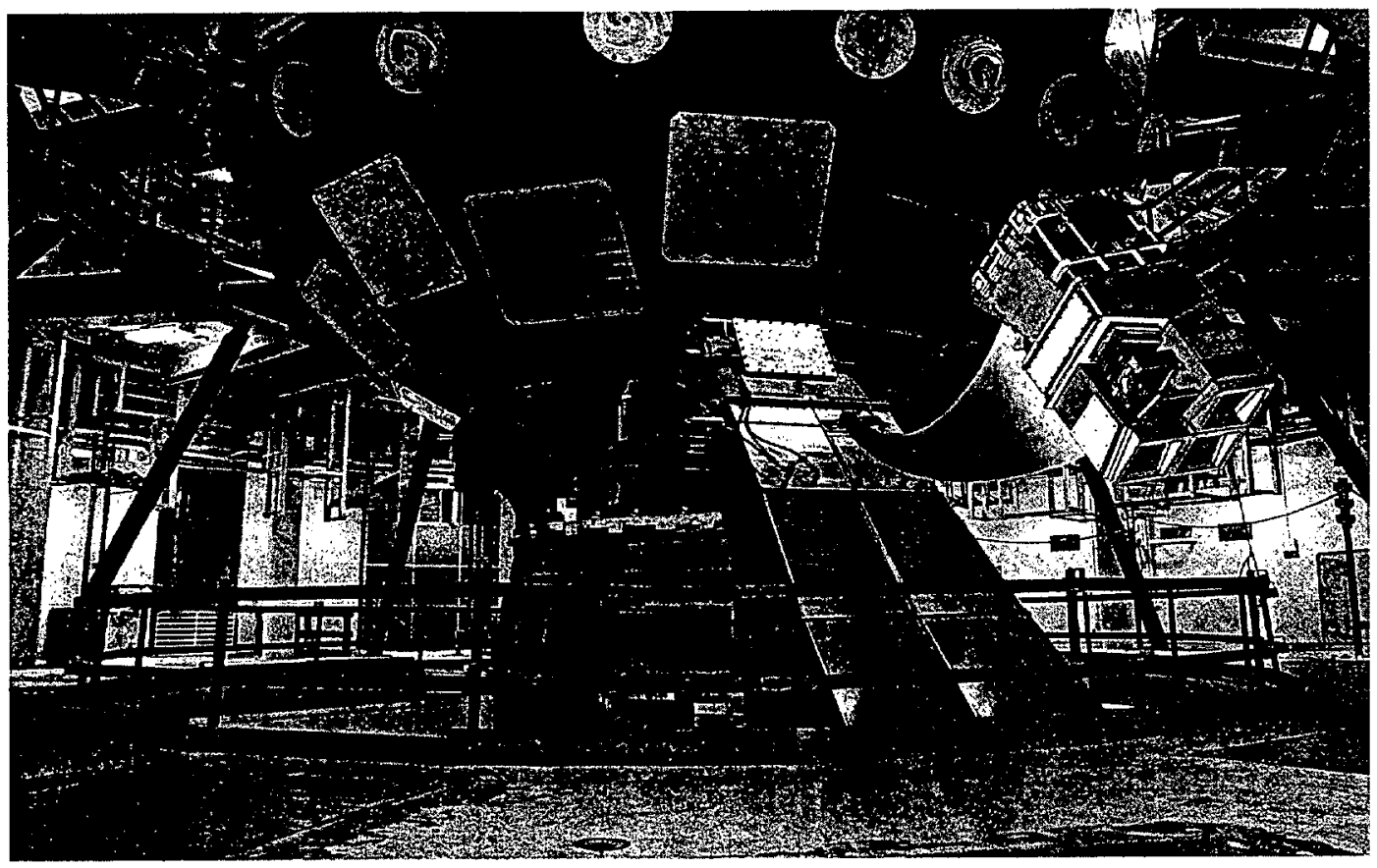

Final Optics Assembly simulated in target bay.

\section{Overview}

The Laser Science and Technology (LS\&T)

1 Program's mission is to develop advanced solid-state lasers, optics, materials technologies, and applications to solve problems and create new capabilities of importance to the Nation and the Laboratory. A top, near-term priority is to provide technical support to the National Ignition Facility (NIF) to ensure activation success. LS\&T provides the NIF Programs with core competencies and supports its economic viability.

The primary objectives of LS\&T activities in fiscal year (FY) 2001 have been threefold(a) to support deployment of hardware and to enhance lasers and optics performance for NIF, (b) to develop advanced solid-state laser systems and optical components for the Department of Energy (DOE) and the Department of Defense (DoD), and (c) to invent, develop, and deliver improved concepts and hardware for other government agencies and U.S. industry. Special efforts have also been devoted to building and maintaining our capabilities in three technology areas: highpower solid-state lasers, high-power optical materials, and applications of advanced lasers. LS\&T activities during FY2001 focused on eight major areas:

1. LS\&T led major advances in technology and optical component development to improve the lifetime of $3 \omega$ UV optics and enhance NIF's operations and performance capabilities.

2. For the Stockpile Stewardship Program (SSP) at the Sandia National Laboratories (SNL) in Albuquerque, New Mexico, LS\&T completed two advanced solid-state laser systems. Both lasers are currently operated by SNL to support experiments on SNL's Z-machine. 
3. LS\&T continued development of $\mathrm{kW}$ - to MW-class, diode-pumped, solid-state laser (DPSSL) drivers for high-energy-density physics and inertial fusion energy.

4. For the Department of Defense (DoD), LS\&T developed and demonstrated a 13-kW average-power heat-capacity laser as part of a longer term effort to develop a $100-\mathrm{kW}$ class solid-state heat-capacity laser (SSHCL) for missile defense.

5. For nuclear energy applications, LS\&T continued to develop laser-shock peening technology to improve the service lifetime of metal canisters designed for final disposal of high-level radioactive waste and retired weapon components at Yucca Mountain, Nevada. Under cooperative research and development agreements (CRADA) with U.S. industry, we are also developing kWclass solid-state lasers for shock peening and hole drilling of metals.

6. LS\&T continued to push the frontiers of ultrashort-pulse laser and extreme-field science for applications in SSP as well as national defense. For development of $\mathrm{kJ}$ class, ps Nd-glass laser amplifiers and highaverage-power ultrashort laser system, we developed a new, broadband, front-end laser technology utilizing optical-parametric chirped-pulse amplification (OPCPA).

7. Progress continued in the diffractive optics and precision optical figuring areas, where LS\&T worked toward large-scale lightweight diffractive optics for the next generation of space-based optical assets (such as the proposed Eyeglass space telescope), activating production facility for NIF beam sampling gratings, and demonstrating wet-etch optical figuring for producing custom continuous phase plate for NIF and other programs.

8. Advanced laser guide star and adaptive optic systems have been successfully activated at both Lick and Keck Observatories.

\section{Deploying NIF Hardware and Improving NIF Laser Optics and Materials Performance}

LS\&T work on NIF has focused mainly on the deployment of the NIF Final Optics Assembly (FOA) and the development of $3 \omega$ optics processing and treatment technologies to enhance the performance of optics in the FOA.
The FOA converts the laser light from infrared to $U V$ ( $3 \omega$ at $350 \mathrm{~nm}$ ), conditions the beam, and delivers it to the fusion target chamber. It consists of several large-aperture optical components including continuous phase plates for beam smoothing, fused silica vacuum windows, potassium dihydrogen phosphate (KDP) crystals for frequency conversion to $3 \omega$, a wedged focus lens and diffractive gratings for color separation, beam sampling gratings, and debris shields. To extend optics lifetimes in the FOA, we systematically studied the damage initiation mechanisms and measured the rate of damage-growth on optical components. Fused silica is an inherently good optical material for the NIF application, with $>99.999 \%$ of the surface being free of damage. Surface damage is initiated by surface cracks and impurities from the polishing process. The damage typically initiates in small size $<30 \mu \mathrm{m}$ and grows quickly with number of shots at fluences $>5 \mathrm{~J} / \mathrm{cm}^{2}$ for $\mathrm{ns}$ pulses at $3 \omega$ wavelength, creating excessive scatter and beam modulation. Surface damage can also be caused by beam modulation associated with bulk inclusions in some types of fused silica.

We developed a novel three-step approach to minimize damage-initiators and reduce damage-growth on $3 \omega$ optics in NIF. (1) Improve optical finishing process at the manufacturer to provide substrates with fewer defects. We qualified two vendors to manufacture inclusion-free blocks using an axial deposition process similar to that used for preforming of optical fiber without refractory material. We developed a series of surface treatment processes to reduce polish defects. By a combination of acid etching, $3 \omega$ laser conditioning, and magnetorheological finishing (MRF), we were able to achieve $\sim 50$ defects per fused silica optic at $12 \mathrm{~J} / \mathrm{cm}^{2}$ (the goal for $3 \omega$ optics), which is a $100 \times$ improvement in initiator reduction. (2) Preinitiate and mitigate surface damage on optics to eliminate growing craters during postprocessing. We refined a $\mathrm{CO}_{2}$ laser annealing process to spottreat the residual surface damage and halt damage growth on fused silica optics. We also developed a spot machining process to stop surface damage growth on KDP crystals. (3) Perform routine inspection, retrieval, and refurbishment (after remitigation) of optics to stop damage growth in optics during NIF operations. 
Highest quality conventional polish

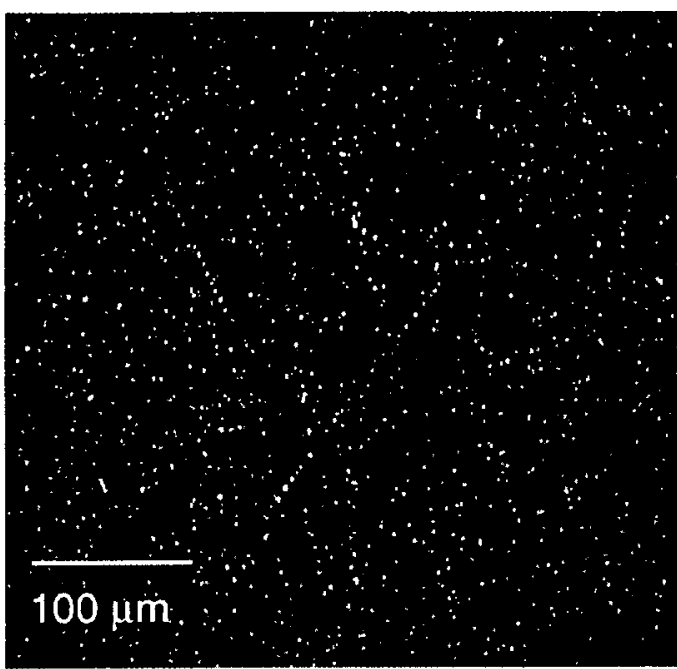

Advanced acid etching, laser conditioning, and MRF polishing

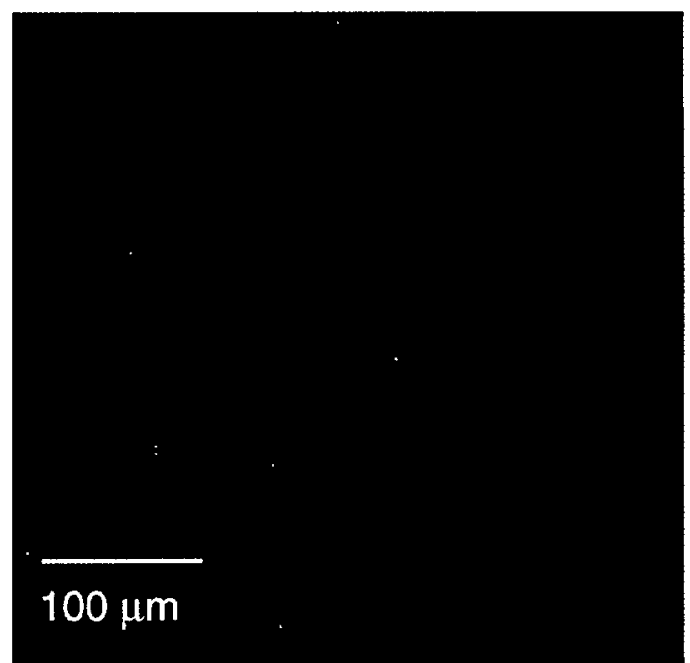

By a combination of acid etching, laser conditioning, and magnetorheological finishing, we produced optics with little or no defects. Dark-field microscopy of as-polished surfaces shows a near-absence of the subsurface damage normally associated with conventional finishing.

To manufacture KDP crystals capable of efficient conversion from $1 \omega$ to $3 \omega$, we developed orthogonal polarization interferometer to map frequency conversion efficiency over the entire KDP crystal area. A machine was built and installed at the NIF crystal manufacturer. To allow easier retrieval of optics for recycling and refurbishment, we completed the redesign of the FOA hardware. Statistical models of laser damage and growth were also developed to estimate lifetime of $3 \omega$ optics and optimize the refurbishment schedule for NIF. With these processing and recycling methods, we believe that the effective lifetime of $3 \omega$ optics will exceed 1000 shots, which meets NIF goals.

Advanced optical component fabrication technologies were also developed to fabricate large-aperture NIF optics including beam-sampling gratings (BSG) and phase plates. A wetchemical process machine and a patterningand-illumination station were assembled to fabricate full-size BSGs with 5- to $30-\mathrm{nm}$ groove depth for damage testing in NIF. We have completed building and testing of production hardware for fabricating NIF BSGs used to perform critical power balance of the 192 NIF beamlines. We are currently beginning pilot production of full-size BSGs to be used on NIF early light. We have also developed controlled wetetching processes for figuring of NIF continuous contour phase plates.

\section{Construction and Testing of Z-Beamlet Completed; Laser Trigger System Delivered}

\author{
Under the auspices of DOE's Inertial
} Confinement Fusion (ICF) Program, LS\&T, in partnership with SNL, completed construction of a laser backlighter system (the Z-Beamlet) for $x$-ray radiography at SNL's Z facility in Albuquerque, New Mexico. The $Z$ facility uses electrical pulsed power to drive a z-pinch implosion, which generates $\mathrm{x}$-rays to drive ICF and high-energy-density physics experiments. We built the terawatt-class Nd:glass solid-state laser utilizing large-aperture optical components retrieved from former Beamlet and Nova lasers. To meet $\mathrm{Z}$-Beamlet specifications $(2 \mathrm{~kJ}$ of $0.53-\mu \mathrm{m}$ laser energy in a picket fence of $<2 \mathrm{~ns}$ duration with a focus spot of $<50 \mu \mathrm{m}$ in diameter), we made a number of modifications to LLNL's Beamlet and utilized optical designs recently developed for NIF. These include: (1) Construction of a new fiber-optic Seed Pulse Generator (SPG) for the Master Oscillator Room (MOR) using NIF's diodepumped ytterbium-silica fiber-laser technology. (2) Increasing the regenerative amplifier ring length with improved stability. (3) Upgrading the plasma electrode Pockels cell (PEPC) to reduce electrode sputtering and improve switching uniformity. (4) Purging amplifiers 
with nitrogen gas to improve cleanliness of amplifier operation. (5) Re-engineering the entire Z-Beamlet computer control to a LabVIEW system using Windows NT, which enabled the laser and electrical pulses to fire simultaneously with synchronization of less than 3 ns. Additionally, LS\&T built beam sensors and alignment systems as well as designed a new final focus system (an analogy of NIF's FOA) to couple the Z-Beamlet laser output into the $\mathrm{Z}$ target chamber. $\mathrm{Z}$-Beamlet was activated in 2001. Its output was used to generate a powerful $x$-ray source for penetrating the z-pinch target. The first images of the $z$-pinch implosion target using the laser backlighter were produced in June 2001. The Z-Beamlet is currently used by SNL to support SSP experiments.

For DOE's ICF program, LS\&T also designed and built an all solid-state $\mathrm{Nd}$ laser that produces near diffraction-limited highenergy pulses at $263 \mathrm{~nm}$ for initiating breakdown in the $Z$ accelerators high-voltage switches. The solid-state laser we built offers several advantages relative to the $248-\mathrm{nm} \mathrm{KrF}$ excimer laser currently used at Sandia. Chief among these are superior beam quality and shorter pulse rise time (several hundred ps) properties expected to reduce switch timing jitter and improve synchronization of the $Z$ accelerator with its diagnostic $x$-ray backlighter pulse.

The laser trigger system generates pulses at $1.053 \mathrm{~nm}$ using an injection-seeded Nd:YLF regenerative amplifier and a four-pass $1-\mathrm{cm}$ Nd:glass rod amplifier. A phase conjugator is used to maintain wavefront quality ( 2 to 3 times diffraction limit). The 10 -ns output from

The Beamlet laser was modified and reassembled at Sandia for use as a backlighter beam on the $Z$ accelerator.

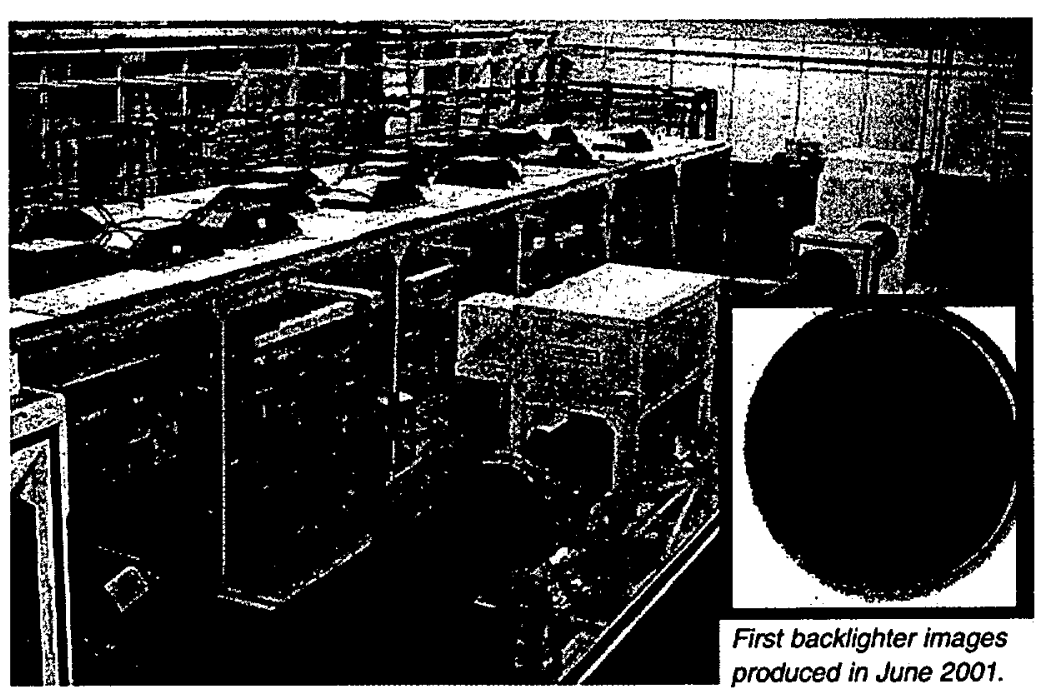

the four-pass amplifier feeds a single-pass $1-\mathrm{cm}$ rod amplifier and a pair of BBO crystals for frequency conversion to the fourth harmonic. We were able to generate an output of $850 \mathrm{~mJ}$ at $263 \mathrm{~nm}$ with $3.6-\mathrm{J}$ incident radiation at the $1.053 \mathrm{~nm}$. A maximum harmonic conversion efficiency of $25 \%$ was achieved, limited by two-photon absorption at $263 \mathrm{~nm}$. The laser trigger system was delivered to Sandia in September 2001 and is currently operated by $S N L$ as a diagnostic tool in the $\mathrm{z}$-pinch experiments.

\section{kW- to MW-Class Solid-State Laser Technology for Inertial Fusion Energy}

Under the support of the DOE Defense Programs, LS\&T continued to build a kW-class diode-pumped solid-state laser (Mercury) as the first in a series of next-generation lasers for inertial fusion energy (IFE). The Mercury laser system design is based on an IFE scalable architecture with goals achieving $10 \%$ electrical efficiency and 10-Hz operation for $100 \mathrm{~J}$ per 5-ns pulses. Three component technologies were developed for this high-power, solid-state laser fusion driver: (1) large-scale, highperformance diode lasers; (2) high-speed gas cooling of the gain media; and (3) large $\mathrm{Yb}^{3+}: \mathrm{Sr}_{5}\left(\mathrm{PO}_{4}\right)_{3} \mathrm{~F}$ (Yb:S-FAP) crystal amplifiers. Our primary goals in FY2001 were to build and characterize the laser system with $320 \mathrm{~kW}$ of peak diode power (4 backplanes) and seven neodymium-doped glass slabs mounted in the gas-cooled amplifier. The $\mathrm{Nd}$ :glass slabs serve as surrogate material in the amplifier assembly until the Yb:S-FAP crystalline slabs are completed. The glass slabs are mounted in an aerodynamic aluminum vane structure to allow turbulent helium gas to flow across the faces. The concept of face cooling is advantageous over other technologies in that the thermal wavefront distortions are minimized, low order, and easily correctable. Measurements of the diode light delivery efficiency, uniformity, and polarization were made with $160 \mathrm{~kW}$ of diode power ( 2 backplanes). The remaining two backplanes were fabricated and are currently being assembled into the laser system for integrated tests. Propagation experiments of the seed beam through the amplifier were conducted along with the activation of the diagnostics packages. Major laser components 


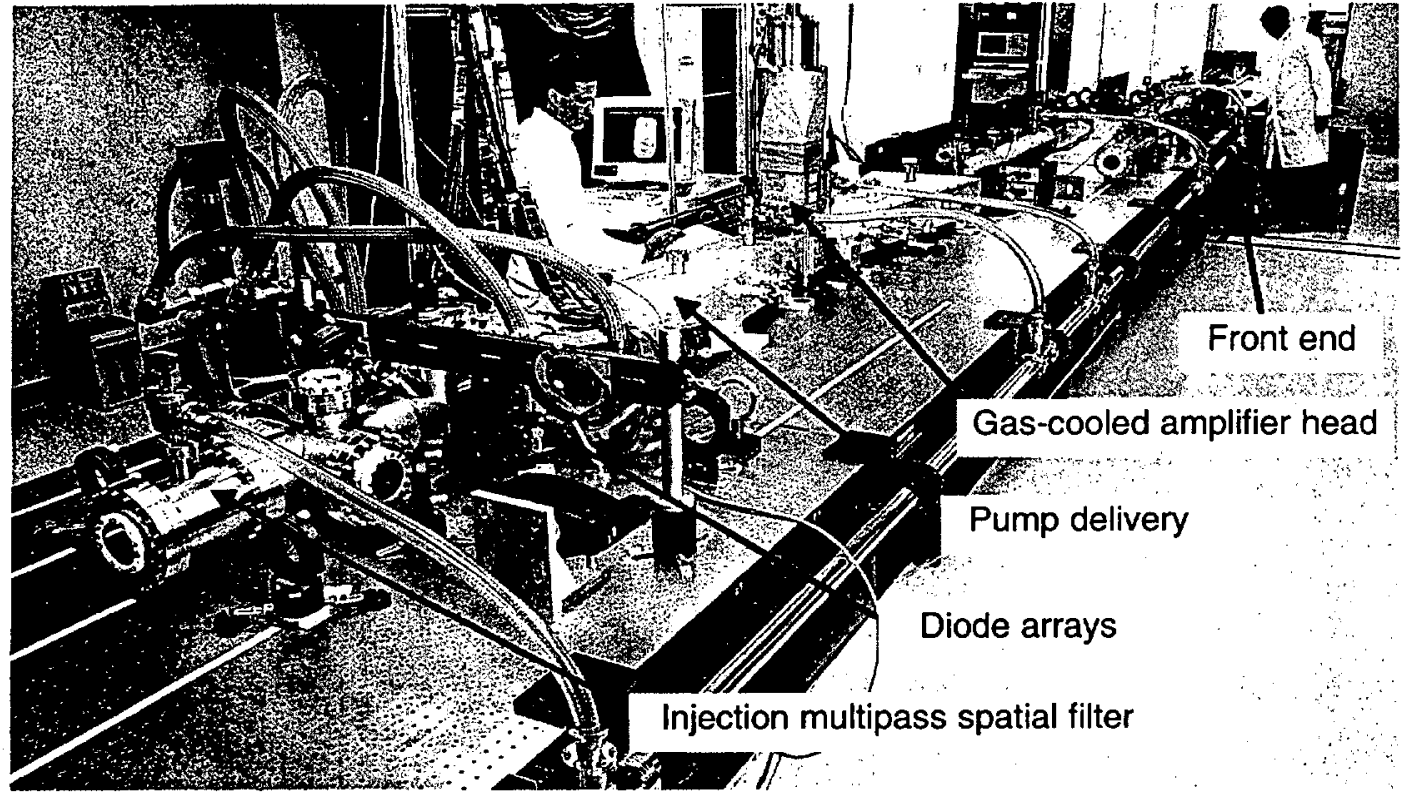

such as YLF oscillator, multipass filter, pump delivery system, and one gas-cooled amplifier were fully assembled and characterized. In the final configuration, the Mercury laser will require two amplifiers in order to produce $100 \mathrm{~J}$ of $1.047-\mu \mathrm{m}$ light.

The growth and fabrication of the Yb:S-FAP slabs constitute another major element of our program objectives. Our goal was to produce at least two half-sized defect-free crystals, which could be bonded into one large $4 \times 6 \mathrm{~cm}^{2}$ crystal. Growth efforts at LLNL and at Northrop Grumman Poly-Scientific, Blacksburg, Va., our industrial collaborator, resulted in the production of eight half-sized crystals that have been bonded together at ONYX Optics Inc., Dublin, Ca., to form four full-sized slabs. The slabs are in the final finishing and coating stages. Yb:SFAP crystals were chosen as the preferred gain media to neodymium-doped glass because they offer higher energy storage, reducing laser diode cost, and a practical gain cross section. In addition, the high thermal conductivity of Yb:S-FAP permits operation at $>10 \mathrm{~Hz}$ repetition rates. A total of 14 slabs will eventually be required for the two amplifiers. The diode bars needed to pump or excite the Yb:S-FAP crystals have been developed at Coherent Inc., Santa Clara, Ca., and are now commercially available. The packaging technology, required to cool the diode bars was developed at LLNL (called V-BASIS), meets the stringent requirements pertaining to peak power, bandwidth, wavelength chirp, and reliability. Our goal was has been bonded. to fabricate one-half or 144 of the diode packages or "tiles" needed for Mercury and mount them on a copper-cooling block. Over 150 tiles were fabricated and tested. Through a close relationship with Directed Energy Inc., Fort Collins, Colo., off-the-shelf pulsers were upgraded to accommodate Mercury operating conditions and are now available commercially.

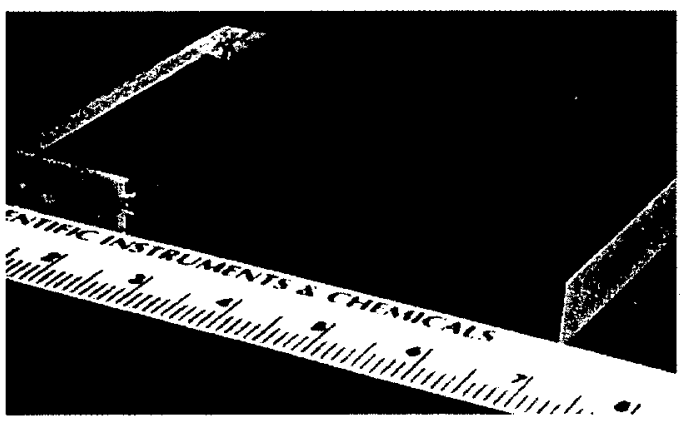

A full-sized Yb:S-FAP slab (amplifier medium) that

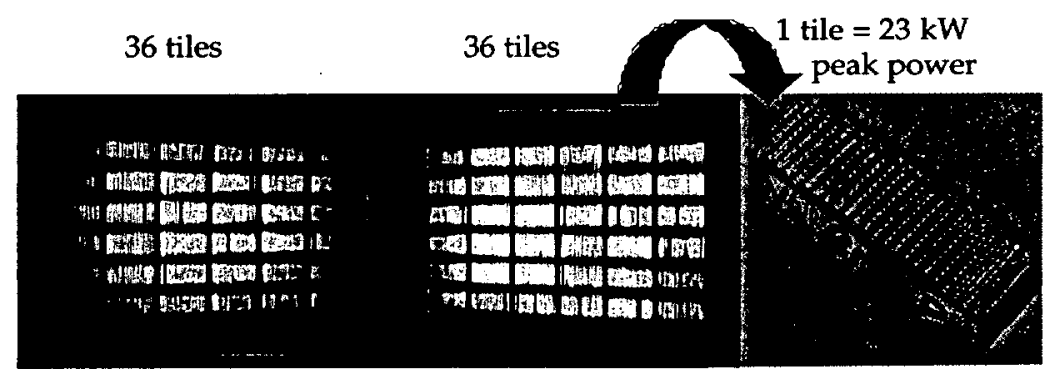

A picture of diode tiles (pump laser) firing producing up to $160 \mathrm{~kW}$ of peak power at $900 \mathrm{~mm}$.
The Mercury laser laboratory during alignment tests with major components labeled. 
The performance of the $160-\mathrm{kW}$ diode package firing at $10 \mathrm{~Hz}$ has been characterized.

Activation of the remaining two backplanes is imminent and will allow us to pump the surrogate glass slab from both sides.

\section{Solid-State Heat Capacity Laser for the Department of Defense}

Under the support of the Army's Space and Missile Defense Command and in collaboration with industrial partners (Raytheon, Litton, and others), LS\&T is developing a high-averagepower (100-kW class), diode-pumped solidstate, heat-capacity laser technology for application in tactical short-range air defense missions. The ultimate vision is an electrically powered, diode-pumped, solid-state weapon that can be deployed on an electric vehicle. To establish a solid technical basis for the heatcapacity laser operation and risk reduction, we built and tested two flashlamp-pumped Nd:glass laser prototypes: 3-disk and 9-disk modules. In 2001, we completed the construction and testing of the 9-disk module. This 9disk module is designed to have $10-\mathrm{kW}$ average output power and deliver laser pulses with beam quality $<3 \times$ diffraction limit and energy of $500-\mathrm{J} /$ pulse at $20 \mathrm{~Hz}$ for 10 -s bursts. We delivered this laser to the Army's High Energy Laser Systems Test Facility (HELSTF) at the White Sands Missile Range, New Mexico, to support material interaction testing. In August, we successfully demonstrated heat capacity operation for full $10 \mathrm{~s}$ with an average power of $13 \mathrm{~kW}(639 \mathrm{~J} /$ pulse at $20 \mathrm{~Hz})$. Currently, the laser is operating with a stable

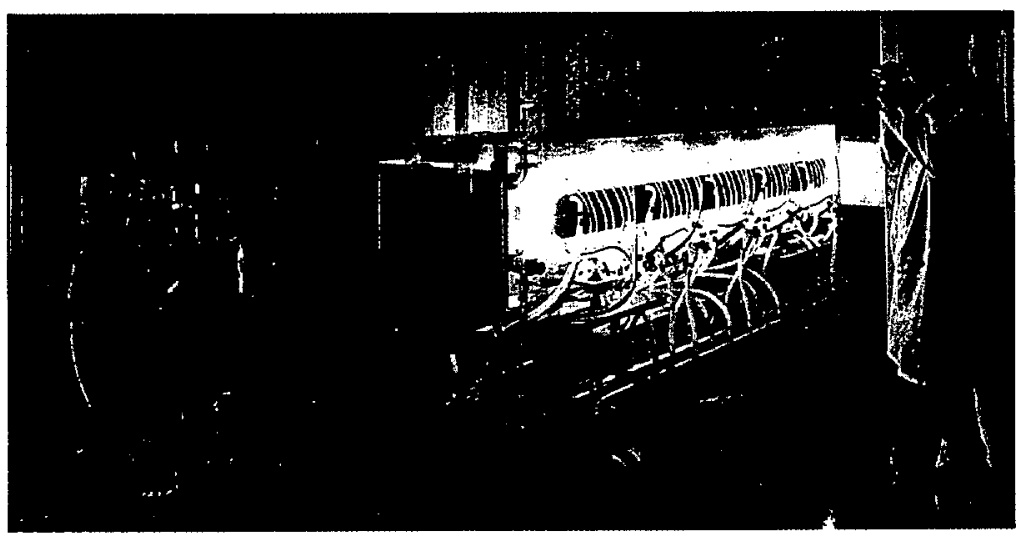

The 10-kW laser system installed at HELSTF to support material interaction testing.

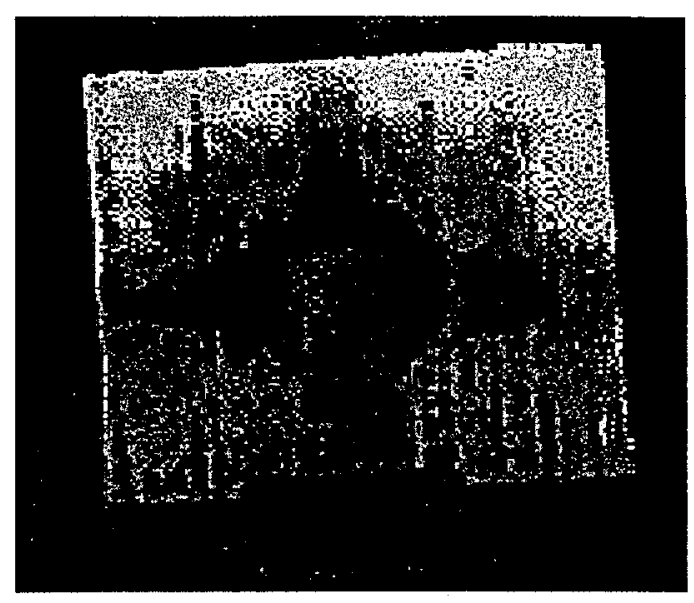

A 1-in.-thick aluminum target after a 2-sec laser burst produced a hole through it.

resonator, which is ideally suited to the target interaction experiments. Using a stable resonator with an output coupling of $29 \%$, we extracted up to $1000 \mathrm{~J} /$ pulse from the amplifier. A beam quality of approximately $3.5 \times$ the diffraction limit was demonstrated with an unstable resonator with no deformable mirror correction. Components for improving beam quality, such as deformable mirrors (DM), DM control electronics, and laser diagnostic sensor packages, have been assembled and tested. With the new DM and an unstable resonator, we expect to achieve the desired goal of $2 \times$ the diffraction limit over the entire 10 -s run time.

Using the 9-disk prototype heat-capacity laser described above, we performed a series of target interaction experiments. During these experiments, the heat-capacity laser was operated at $3 \mathrm{~Hz}$ with energy of $650 \mathrm{~J}$ per pulse. The laser beam footprint is roughly square with a 6- $\times 6.5-\mathrm{mm}$ spot on the target. The irradiation pulse has a temporal envelope of 300 to $400 \mu \mathrm{s}$ and consists of several relaxationoscillation spikes with peak intensities near $1 \mathrm{MW} / \mathrm{cm}^{2}$. We successfully removed about $0.9 \mathrm{~cm}^{3}$ of aluminum (11 mm deep) after irradiation with 38 laser pulses. To guide future target interaction experiments, we continued to develop numerical models to simulate the material removal process using hydrodynamics codes to model the vaporization and material ejection process. During a ribbon-cutting ceremony at HELSTF, we fired the 9-disk laser at a 1-in.-thick aluminum target and successfully penetrated the target in $2 \mathrm{~s}$.

The development of a 100-kW-class diodepumped neodymium-doped gadolinium 


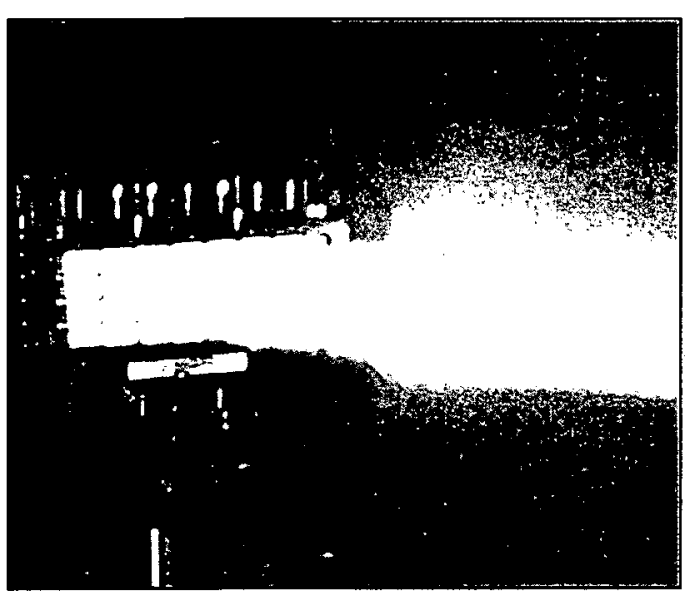

A $100-k W$-class diode array module in operation. It was developed for pumping of high-average-power solid-state lasers.

gallium garnet (Nd:GGG) crystalline laser is proceeding rapidly. The diode-pumped Nd:GGG heat-capacity laser will have better thermal characteristics and operating efficiency enabling us to scale the output power to $100 \mathrm{~kW}(500 \mathrm{~J} / \mathrm{pulse}$ at $200 \mathrm{~Hz})$. We have made significant progress toward the growth of high-quality Nd:GGG boules. Litton Airtron Synoptics, Charlotte, N.C., is now routinely growing $15-\mathrm{cm}$-diameter Nd:GGG boules with high optical quality. We have also completed the fabrication and testing of a $42-\mathrm{kW}$ laser diode array for pumping of Nd:GGG slabs. This high-power diode module is constructed from 280 edge-emitting laser-diodes mounted on a backplane packaged by 28 closely packed silicon microchannel monolithic tiles (SiMMs) arranged in $4 \times 7$ configuration. The brightness of the array is approximately $1 \mathrm{~kW} / \mathrm{cm}^{2}$ at a $10 \%$ duty factor. In order to utilize fully the light emitted from laser-diode bars, we designed microlenses to collect radiation along the fast axis and were able to reduce the beam divergence angle from $30^{\circ}$ to $<1^{\circ}$. The SiMMs package represents a significant breakthrough in the high-power diode-array packaging technology enabling us to scale the output of 2-D diode arrays to $100 \mathrm{~kW}$ or larger with extremely high brightness. Using diode bars procured from Coherent Semiconductor Group, Santa Clara, Ca., we successfully achieved $1.5 \mathrm{~kW}$ of output power from a single tile (10-bar SiMMs package) with electrical efficiency approaching $45 \%$. Using a diode array as pumping source, we completed emission cross-section and thermal deposition measurement on Nd:GGG. We will demonstrate a small-scale Nd:GGG heatcapacity laser at $200 \mathrm{~Hz}$ in 2002 and replicate several features that would be found in a fieldable Army vehicle.

\section{Advance Solid-State Lasers for Government and Industry}

\section{Laser Peening Increases Fatigue Lifetime and the Corrosion Resistance of Metals \\ LS\&T has an ongoing CRADA with Metal} Improvement Company, Inc., Paramus, N.J., to develop and deploy a high-throughput laser peening technology to improve fatigue resistance of metals. Initial applications will significantly improve the service lifetime of military and commercial jet engines.

In a joint research effort with the Yucca Mountain Project (YMP), we are evaluating laser peening as a technique to improve the corrosion resistance and service lifetime of metal canisters designed for final disposal of high-level radioactive waste, dismantled reactors, and retired weapon components. Nuclear waste around the country will be stored underground at Yucca Mountain in welded canisters of Alloy 22. These canisters are required to last 10,000 years without leakage. However, the process of welding the end caps on these canisters can cause tensile stress that allows defects to grow into cracks and accelerate corrosion. Previous LS\&T work has demonstrated that laser peening can transform tensile stress into compressive stress deep into the material and prevent the growth of such cracks. In recent tests, we have found that laser peening not only stops crack propagation in welds but also retards the overall corrosion rate of metal. By optimizing the process parameters such as laser pulse duration ( 10 to $30 \mathrm{~ns}$ ), fluence intensity (50 to $300 \mathrm{~J} / \mathrm{cm}^{2}$ ) and number of treatment pulses, we were able to induce compressive stress deep into metals such as titanium, aluminum, steel, Alloy 22, etc. Compressive residual stress extending to depth of several millimeters has been achieved with laser pulses at various fluence intensities. We conducted a series of stress corrosion cracking (SCC) and surface corrosion experiments on 304 and 316 stainless-steel weld in a boiling $\mathrm{MgCl}_{2}$ solution. Our test results indicated that laser peening increases the free corrosion potential of metal, reduces the passive current density, and 


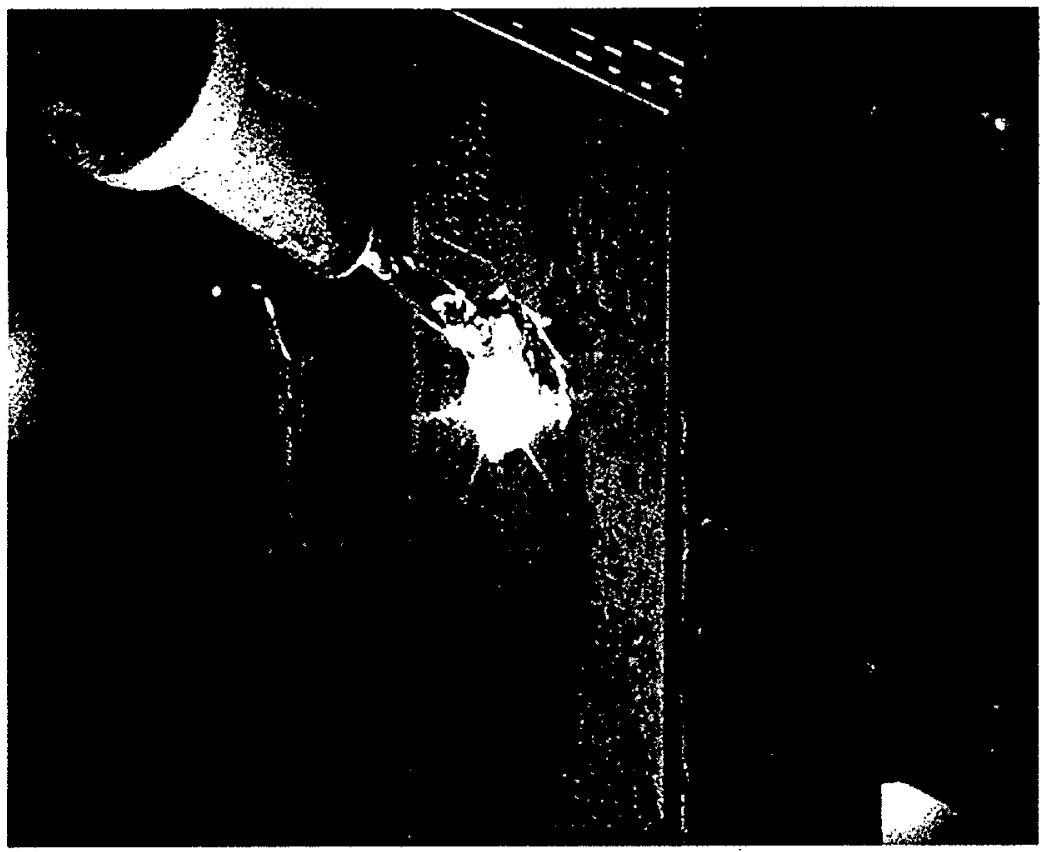

The Lasershot ${ }^{\mathrm{sm}}$ Marking System won an R\&D 100 Award in 2001. The technology imprints an identification mark that is permanent, machine readable, high resolution without weakening the surface of the marked part. In August 2001, NASA put three LLNL samples aboard the STS-105 space shuttle and subsequently bolted them on the space station facing the slipstream solar wind. The peenmarked parts will be examined after one year.

retards SCC on metals. We assembled a hightemperature reactor to perform SCC experiment on large-size (ft-scale) test samples. Laser peening was performed on a selected area of the welds. Under highly corrosive environment $\left(\mathrm{MgCl}_{2}\right.$ solution at $\left.160^{\circ} \mathrm{C}\right)$, the unpeened weld area showed cracks and corrosion within 5 days, while the laser-peened weld area showed no signs of cracking or corrosion even after 10 days of exposure. Cracks originating from the unpeened area appear to propagate, bypass, and cease at the peened zone. We are working closely with industry to commercialize this technology. Besides application in the YMP nuclear waste disposal for the government, there are potential applications of this technology for the U.S. industry in improving reactor safety and reliability and in extending the operational life of reactor components (internals, tubes, bolts, and pins) so that boilingwater reactors and pressurized water reactors will have a higher service life and lower operating cost.

We are also developing a laser peenmarking system to create permanent, high-resolution identification marks on safety-critical metal parts, without weakening the part. LS\&T and
Metal Improvement Company, Inc., are working with the National Aeronautics and Space Administration to determine the efficiency of laser peenmarking to identify and track millions of parts used in the space program. In August 2001, three laser peenmarked parts were put aboard the STS-105 shuttle and subsequently bolted onto the space station to face the slipstream solar wind. After one year, they will be retrieved and examined to evaluate how well they held up in the hostile space environment.

\section{Short-Pulse, High-Average-Power} Solid-State Laser for Micromachining

Under the support of DOE's Stockpile

Stewardship and Management Program, LS\&T continues to develop high-averagepower, short-pulse solid-state lasers and corresponding applications for use as precision cutting and drilling machines in the stockpile life extension process. The lasers developed for precision machining employ numerous advanced laser technologies of the LS\&T Program. These technologies include fiber mode-locked oscillators, solid-state regenerative and power chirped-pulse amplifiers using Ti:sapphire or direct diode-pumped Yb:YAG as gain media, optical parametric chirped-pulse amplifiers (OPCPA), and high-power multilayer dielectric gratings. These laser systems have an average output in the range of 5 to $100 \mathrm{~W}$ and pulse duration of 10 to $2000 \mathrm{fs}$. During the past year, LS\&T reactivated the short-pulse laser systems currently installed in Oak Ridge Y-12 Plant and LLNL's High Explosives Applications Facility (HEAF) to machine weapon parts, explosives, and energetic materials. Short-pulse laser processing enables machining of these components with high precision and negligible collateral damage. We were able to cut high explosives with no evidence of detonation or deflagration. For ICF and the Defense and Nuclear Technologies Directorate (DNT), we have also made good progress in the drilling of sub- $\mu \mathrm{m}$ holes through the Be capsules and sculpting of high-quality features on fusion targets. We were able to generate surface profiles with $<\mu \mathrm{m}$-scale roughness on polyimide, copper, and alumina targets. The short-pulse lasermachining tool significantly improves the precision and repeatability of the micromachining process. Under a work-for-others contract, 
LS\&T continues to develop a 100 -W-class picosecond, $\mathrm{KHz}$, solid-state laser system for precision drilling of shaped holes in metal.

\section{High-Energy Ultrashort-Pulse Laser Technology}

- With support from the Laboratory Directed Research and Development (LDRD) Program, LS\&T has recently developed a new front-end technology utilizing optical parametric chirpedpulse amplification (OPCPA) to replace the regenerative amplifier used in a variety of chirped-pulse amplifiers, including the Nova petawatt, Falcon, and other short-pulse systems. The wavelength and pulse energy level obtained from this OPCPA is ideal for seeding kJ-class Nd:glass amplifiers, such as NIF and other high-energy ultrashort-pulse laser systems. Previously high-energy lasers employing chirped-pulse amplification (CPA) were built on a hybrid (Ti:sapphire-Nd:glass) laser technology. One difficulty with the hybrid laser system is its low pulse contrast and generation of prepulses by the regenerative amplifier. Single-pass OPCPA eliminates prepulses originating from regenerative amplifiers and reduces the amplified spontaneous emission (ASE) by approximately one order of magnitude compared to Ti:sapphire. It offers additional advantages when compared to regenerative chirped-pulse amplification: low thermal aberration, greater wavelength flexibility, higher gain, high beam quality, and lower $B$-integral as a result of short beam path through the gain medium. In 2001, we built a compact OPCPA using a commercial frequency-doubled Q-switched Nd:YAG laser as pumping source. Three $\beta$-barium borate (BBO) crystals were used as the gain media. Under the type I angular phase-matching condition, two crystals were configured as preamplifiers and one was used as the power amplifier. We have successfully demonstrated high gain $\left(\sim 10^{7}\right)$, high conversion efficiency $(>20 \%)$, good amplified pulse beam quality $\left(M^{2}<2\right)$, and high bandwidth fidelity in OPCPA (30 fs). We anticipate widespread use of OPCPA as frontend technology for glass-based petawatt laser systems and high-average-power systems. In the future, it may be possible to exploit the full bandwidth capability of OPCPA to produce $\mathrm{kJ}$-class pulses with duration of several tens of femtoseconds. This would potentially allow. focused intensities of $10^{24} \mathrm{~W} / \mathrm{cm}^{2}$ or higher for experiments in the extreme-field science.

To study ultrafast response of materials for the Stockpile Stewardship Program, we continue to develop an ultrafast $x$-ray source based on Thomson scattering of fs laser pulses (Falcon laser) from $100-\mathrm{MeV}$ relativistic-electron bunches. During FY2001, work on the integration of the multiterawatt ultrashort-pulse Falcon laser system and LLNL's linear accelerator (linac) began. We tested several techniques for timing synchronization between electron bunch and laser pulse to $\sim 2$ ps accuracy. The linac was reconfigured for installation of the 5-MeV photoinjector. Considerable advances have also been made to the Falcon and photoinjector laser systems. Thomson scattering with the photoinjector was successfully

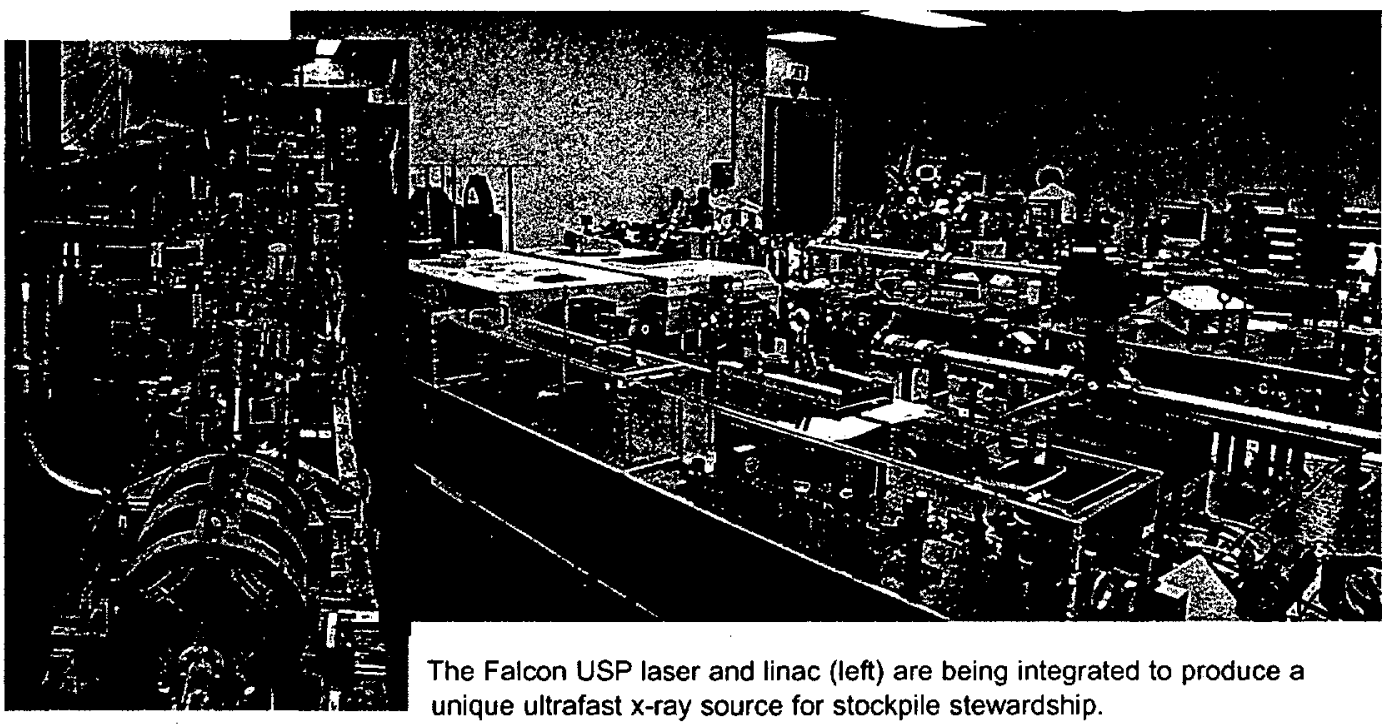


Thomson scattering with photoinjector was demonstrated.

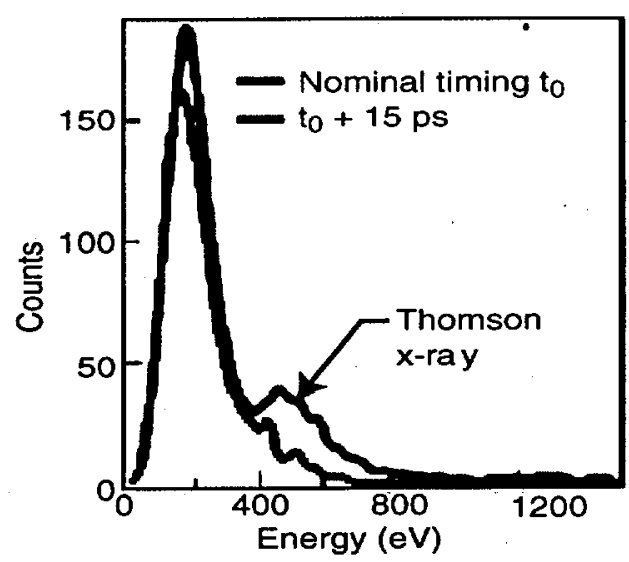

demonstrated; the photoinjector generated $600-\mathrm{eV} x$-ray photons by scattering of the $5-\mathrm{MeV}$ electron beam with the 400 -fs laser pulses from Falcon. A new final power amplifier is being installed that will increase Falcon laser output by four times. We have developed a new front-end for Falcon based upon a hybrid system using both OPCPA and a Ti:sapphire amplifier. The hybrid design enables us to increase the pump efficiency and energy of the compressed pulses and simplify the overall architecture by eliminating the regenerative amplifier. We plan to complete the integration activities in 2002 . When completed, this ultrafast $x$-ray source will be used to probe the dynamics of shock propagation and phase transitions in high- $Z$ metals that are relevant to Stockpile Stewardship.

\section{Large-Scale Diffractive Optics and Adaptive Optics for Space, NIF, and Petawatt Applications}

LS\&T continues to design and produce large-aperture high-efficiency diffractive optics for NIF and petawatt laser facilities around the world. These advanced optical components include meter-scale gold petawatt gratings, multilayer dielectric reflection gratings for pulse compression, fused silica transmission gratings, Fresnel lenses, and ultrathin optics $(<1 \mathrm{~mm})$. We are also advancing the adaptive optics and solid-state laser technologies for ground-based astronomy in the next decade.

\section{Meter-Scale Diffractive Optics for Petawatt Lasers}

During FY2001, under work-for-others contracts, we completed the fabrication of several 94-cm-diameter gold diffraction gratings for Rutherford Appleton Laboratory (RAL) in the United Kingdom and the University of Osaka, Japan. RAL has recently upgraded their 100-TW laser system using LLNL's large-aperture diffraction grating to generate subpicosecond pulses for high-intensity laser/matter interaction experiments. LLNL's large-aperture diffraction grating enables RAL to compress 500-J, 500picosecond pulses to achieve petawatt $\left(10^{15} \mathrm{~W}\right)$ of power and $10^{21} \mathrm{~W} / \mathrm{cm}^{2}$ at target. In 2001 , we successfully modified the exposure system (used originally for making LLNL's Petawatt laser gratings) to increase fringe stability during patterning of the grating. These gratings (with 1480 to 1800 line-pairs $/ \mathrm{mm}$ ) are currently optimized for high-efficiency and flat wavefront at the nominal 1053-nm use wavelength. The damage threshold is greater than 400 $\mathrm{mJ} / \mathrm{cm}^{2}$ for a 10 -ps pulse. The diffraction efficiency of the gold-overcoated petawatt compressor gratings is $>93 \%$ in beam footprint, at

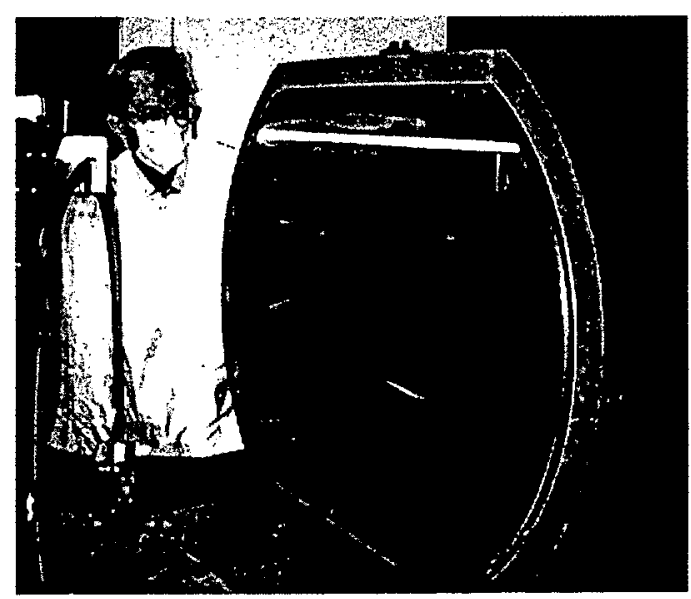

A meter-scale grating undergoing a wavefront test. LLNL supplies petawatt pulse compressor gratings to a variety of facilities both U.S. and foreign.
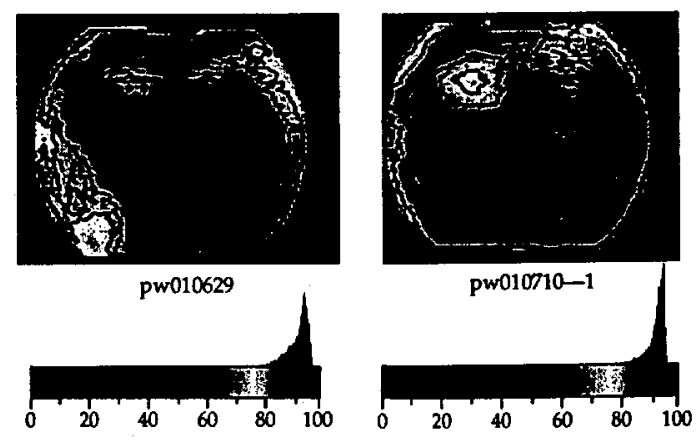

Full-aperture diffraction efficiency of two compressor gratings. Dashed lines show footprint of the compressed beam. 
use-wavelength and $54^{\circ}$ incidence angle, which represents the best uniformity we have been able to achieve to date at this scale. LS\&T is also developing large-aperture multilayer dielectric transmission and reflection gratings using cold-cathode ion-beam etching techniques for producing high-average-power ultrashort-pulse laser for laser machining and NIF applications. Using the dielectric reflective gratings, we were able to significantly improve the efficiency of pulse compression in highpower chirped-pulse amplifiers.

\section{New Wet-Etching Process for Figuring Large-Aperture and Ultrathin Optics}

With support from the Laboratory Directed Research and Development (LDRD) Program, LS\&T has recently developed a low-cost wetetching tool for precision optical figuring and finishing of large-aperture and ultrathin optical components. This wet-etch figuring (WEF) method uses applicator geometry and surface tension gradients (the Marangoni effect) to confine the footprint of the flowing etchant (hydrofluoric acid) on the surface. In contrast to the conventional methods using abrasive slurries or ion milling, no mechanical or thermal stresses or residues are applied to the optic by this process. We have also developed a realtime interferometer to measure the thickness of the optical material while surfacing and frguring. This enables us to control the placement and dwell time of the wetted zone. We built both circular and linear etching toolheads for two- and one-dimensional (2- and 1-D) figuring. Several phase-correction and beam-shaping optics were fabricated using the 2-D WEF tool. An 80-mm-aperture corrective optics was recently fabricated for the Atomic Weapons Establishment (AWE), U.K., to correct wavefront aberrations in high-power lasers. The optic surface contour specified by AWE requires a maximum excursion of $12 \mu \mathrm{m}$ over this aperture. We were able to figure the surface profile within $100 \mathrm{~nm}$ of the target goal.

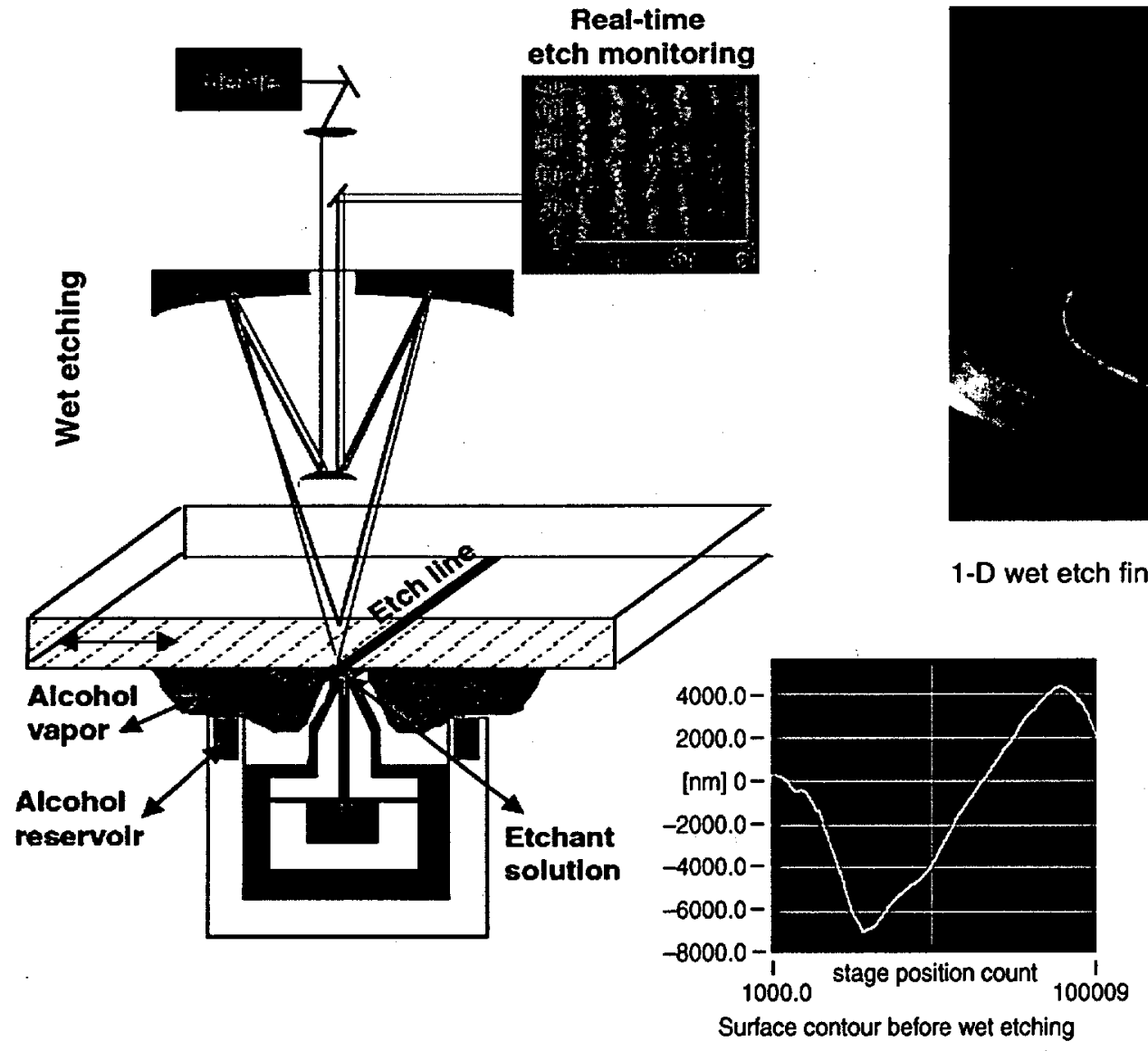

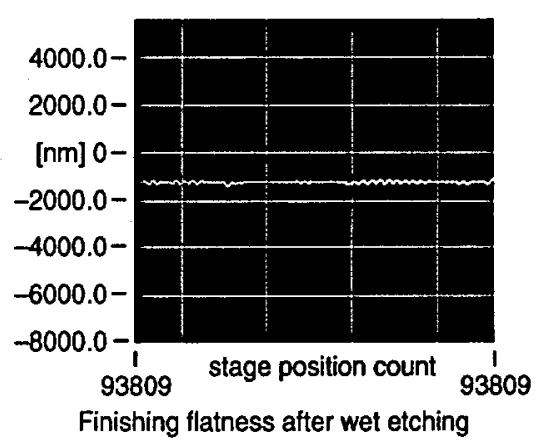

LS\&T developed $1-D$ and $2-D$ wet etch finishing tools with real-time interferometric feedback control. 
WEF is an ideal technology for the fabrication of large-aperture phase-modifying optics and optically flat optics. It is particularly useful for precision figuring of very thin $(\ll<1 \mathrm{~mm})$, lightweight optics for use in space and astronomy and high-power laser systems in which nonlinear effects due to bulk transmissive optics need to be minimized. LS\&T continues to improve the precision of the WEF machine and to use it for figuring of continuous phase plate for NIF.

\section{Lightweight Diffractive Optics for New Space Telescope: Eyeglass}

Working with the Physics and Advanced Technology (PAT) Directorate, LS\&T continues the development of a very largeaperture (25- to 50-m) diffractive space-based telescope (Eyeglass). Diffractive telescopes using thin-membrane Fresnel lenses offer several advantages over telescopes using mirrors. Thin-membrane lenses are lightweight $\left(\sim 0.1 \mathrm{~kg} / \mathrm{m}^{2}\right.$ areal density), packageable, and space deployable. During the past years, we built and tested a color-corrected diffractive telescope using a 50-cm-diameter, silica f/100 Fresnel lens. A near-term goal is to demonstrate that the technology can be scaled up to much larger size and engineered for deployment in space. In this context, we are developing technologies to fabricate a 5-m-diameter Fresnel lens. We completed the detailed design of this lens and the testing of a thin, foldable prototype in 2001. The Fresnel lens

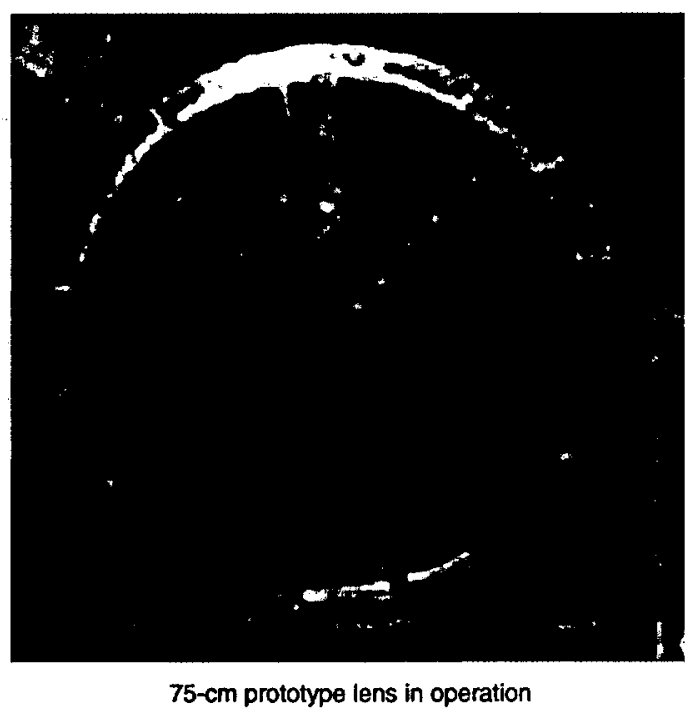

is composed of 81 panels approximately $1 \mathrm{~m}$ wide and $0.7 \mathrm{~mm}$ thick, patterned lithographically and joined together using metallic tabs. As a first step in technology development, we patterned and assembled a six-segment, foldable Fresnel lens on 75-cm-diameter, 1-mm-thick fused silica plates and examined its focus quality when illuminated by a monochromatic, collimated beam. We were able to demonstrate a nearly diffraction-limited focal-spot shape using the foldable Fresnel lens. We plan to build the $5-\mathrm{m}$ segmented Fresnel lens with metrologically verified optical precision in 2002.

\section{Laser Guide Star Systems for Ground-Based Observatories}

Under the support of LDRD and University Relations Programs (UCDRD and the National Science Foundation Center for Adaptive Optics), LS\&T continues to work with PAT to develop fieldable sodium-layer laser guide star (LGS) systems for use on large astronomical telescopes in the Lick and Keck Observatories. Using an LGS at $589 \mathrm{~nm}$, artificial stars can be created in the direction of observation by laser-induced fluorescence in the mesospheric sodium layer, $90 \mathrm{~km}$ above the earth's surface. Using LGS beacons enables the collection of diffraction-limited images over $60 \%$ of the sky. During the past year, we facilitated, installed, and activated robust and reliable LGS and adaptive optic systems at Lick and

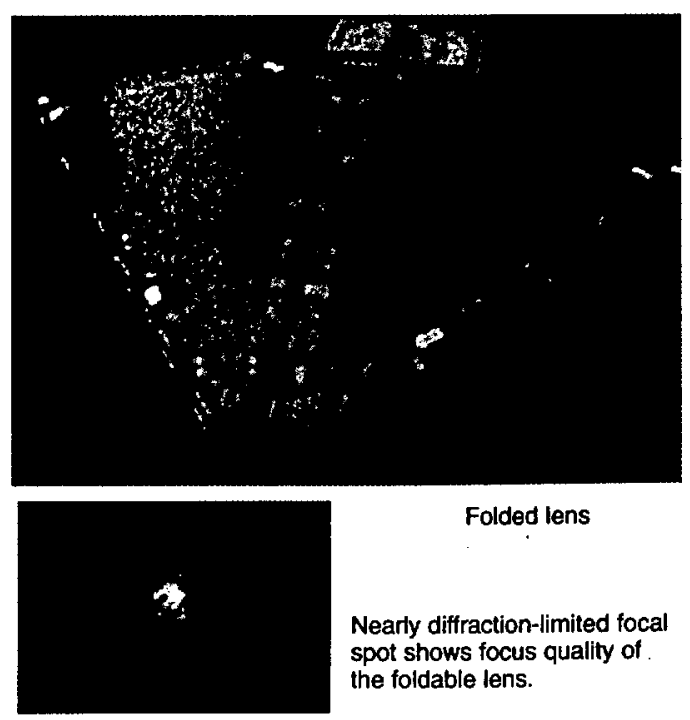

Eyeglass space telescope has demonstrated thin, foldable, six-panel diffractive lens prototype. 
Keck Observatories. These LGSs use frequency-doubled Nd:YAG lasers to pump a dye oscillator, preamplifier, and amplifier, and routinely produce up to $20 \mathrm{~W}$ at $26 \mathrm{kHz}$ with $1.5 \%$ energy stability and a Strehl ratio of 0.647 . The LGS system at Lick is currently being used for routine science observing.
The Keck system has recently completed performance and atmospheric propagation tests. Now we are developing, in collaboration with the European Southern Observatory, an all solid-state fiber guide star laser for next-generation telescopes.

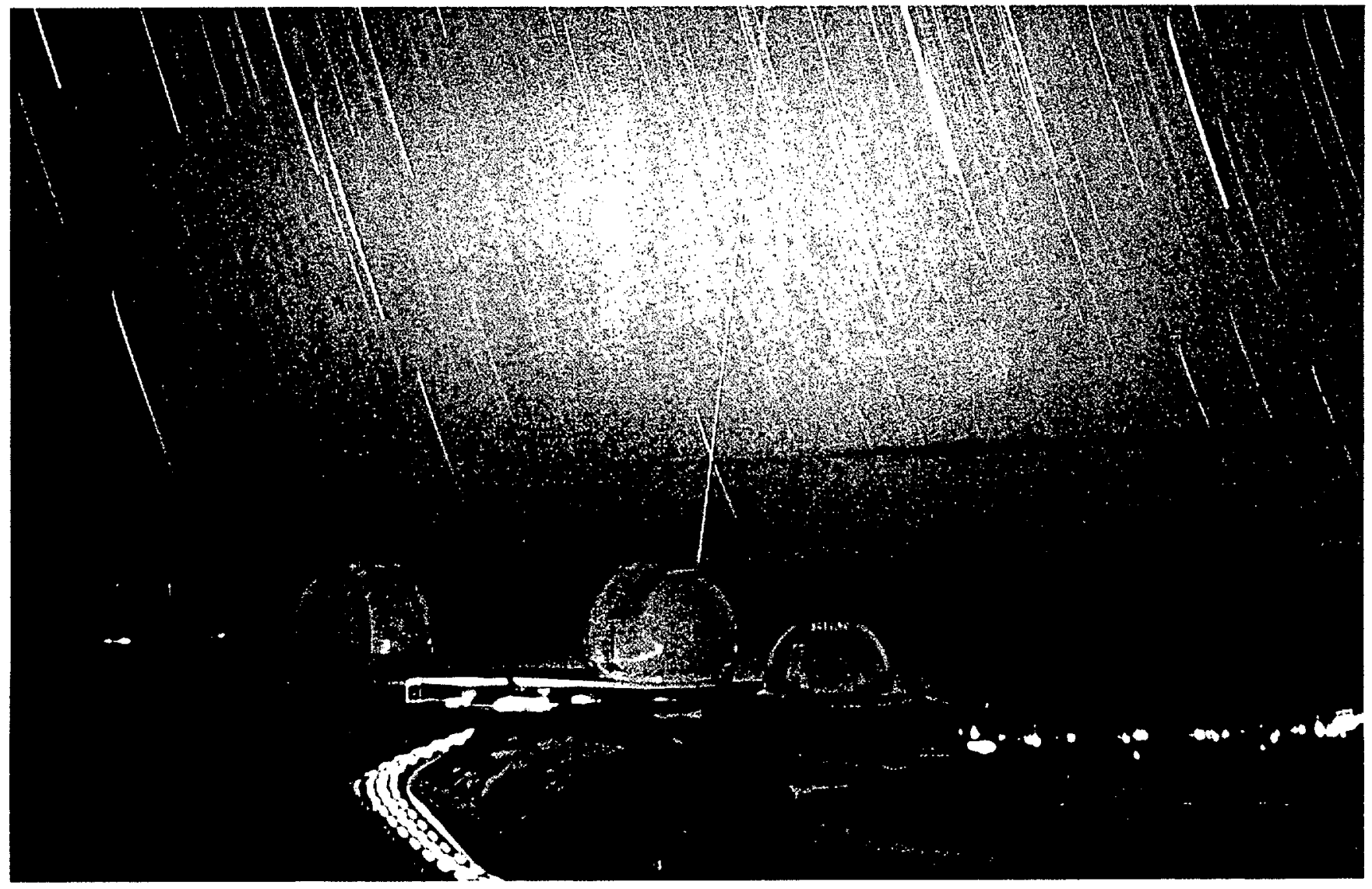

Photo of the Keck "virtual" guide star, showing LLNL-built orange laser beam emerging from the dome of the Keck II Telescope atop 14,000-ft. Mauna Kea volcano in Hawaii. (Photo by John McDonald, Canada-France-Hawaii Telescope Corp.) 


\section{DISCLAIMER}

This document was prepared as an account of work sponsored by an agency of the United States Government. Neither the United States Government nor the University of California nor any of their employees, makes any warranty, express or implied, or assumes any legal liability or responsibility for the accuracy, completeness, or usefulness of any information, apparatus, product, or process disclosed, or represents that its use would not infringe privately owned rights. Reference herein to any specific commercial product, process, or service by trade name, trademark, manufacturer, or otherwise, does not necessarily constitute or imply its endorsement, recommendation, or favoring by the United States Government or the University of California. The views and opinions of authors expressed herein do not necessarily state or reflect those of the United States Government or the University of California, and shall not be used for advertising or product endorsement purposes.

This work was performed under the auspices of the U.S. Department of Energy by University of California Lawrence Livermore National Laboratory under Contract W-7405-ENG-48.

This report has been reproduced directly from the best available copy.

Available to DOE and DOE contractors from the

Office of Scientific and Technical Information

P.0. Box 62, Oak Ridge, TN, 37831

Prices available from (615) 576-8401, FTS 626-8401

Available to the public from the National Technical Information Service, U.S. Department of Commerce, 5285 Port Royal Rd., Springfield, VA 22161

January 2002

UCRL-ID-134972-01 